\title{
The relation of location-specific epicardial adipose tissue thickness and obstructive coronary artery disease: systemic review and meta-analysis of observational studies
}

Fu-Zong Wu ${ }^{1,2,3}$, Kang-Ju Chou ${ }^{2,3,4}$, Yi-Luan Huang ${ }^{1}$ and Ming-Ting $\mathrm{Wu}^{1,3^{*}}$

\begin{abstract}
Background: There is growing evidence about the importance of epicardial adiposity on cardiometabolic risk. However, the relation of location-specific epicardial adipose tissue (EAT) thickness to coronary atherosclerotic burden is still unclear.

Methods: This meta-analysis was used to study the relations between location-specific EAT thickness and obstructive coronary artery disease (CAD). A systemic literature search to identify eligible studies that met the inclusion criteria from the beginning until January 2014 was made. We conducted the meta-analysis of all included 10 published studies. Pre-specified subgroup analyses were performed according to ethnicity, body mass index, diagnostic tools for CAD, and measurement tool if presence of high heterogeneity between studies. Potential publication bias was also assessed.

Results: We identified ten observed studies with a total of 1625 subjects for planned comparison. With regard to the association between obstructive CAD and location-specific EAT thickness at the right ventricular free wall, caution is warranted. The pooled estimate showed that location-specific EAT thickness at the right ventricular free wall was significantly higher in the CAD group than non-CAD group (standardized mean difference (SMD): $0.70 \mathrm{~mm}$, $95 \% \mathrm{Cl}: 0.26-1.13, \mathrm{P}=0.002)$, although heterogeneity was high $\left(I^{2}=93 \%\right)$. It should be clear that only the result of echocardiography-based studies showed a significant association (SMD: $0.98 \mathrm{~mm}, 95 \% \mathrm{Cl}: 0.43-1.53, \mathrm{P}=0.0005$ ), and the result of all included CT-based studies showed a non-significant association (SMD: 0.06 mm, 95\% Cl: -0.12-0.25, $P=0.50$ ). In the subgroup analysis, the "diagnostic tools for CAD" or "measurement tool of EAT thickness" are potential major sources of heterogeneity between studies. With regard to location-specific EAT thickness at the left atrioventricular (AV) groove, it was significantly higher in the CAD group than non-CAD group (SMD: $0.74 \mathrm{~mm}$, 95\% Cl: 0.55-0.92, P $\left.<0.00001 ;\left.\right|^{2}=0 \%\right)$.

Conclusion: Our meta-analysis suggests that significantly elevated location-specific EAT thickness at the left AV groove is associated with obstructive CAD. Based on the current evidence, the location-specific EAT thickness at the left AV groove appears to be a good predictor in obstructive CAD, especially in Asian populations. Furthermore well-designed studies are warranted because of the current limited number of studies.
\end{abstract}

Keywords: Coronary artery disease, Location-specific epicardial adipose tissue thickness, Meta-analysis

\footnotetext{
* Correspondence: wu.mingting@gmail.com

'Department of Radiology, Section of Thoracic and Circulation Imaging,

Kaohsiung Veterans General Hospital, Kaohsiung, Taiwan

${ }^{3}$ Faculty of Medicine, School of Medicine, National Yang Ming University,

Taipei, Taiwan

Full list of author information is available at the end of the article
}

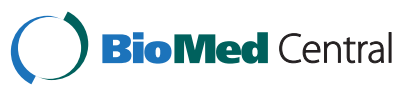

(C) 2014 Wu et al.; licensee BioMed Central Ltd. This is an Open Access article distributed under the terms of the Creative Commons Attribution License (http://creativecommons.org/licenses/by/4.0), which permits unrestricted use, distribution, and reproduction in any medium, provided the original work is properly credited. The Creative Commons Public Domain Dedication waiver (http://creativecommons.org/publicdomain/zero/1.0/) applies to the data made available in this article, unless otherwise stated. 


\section{Background}

Excessive epicardial adipose tissue (EAT) accumulation within the pericardial sac has been suggested to play an important role in the development of coronary artery atherosclerosis through potential paracrine or endocrine mechanism by exerting inflammatory mediators such as TNF-alpha, IL-6, adipocytokines, and leptin [1-5]. Several previous studies have found that CT-measured EAT volume played an important causal role in coronary atherosclerotic burden or coronary artery disease [6-8].

There is increasing attention on the location-specific EAT thickness as a potential predictor in cardiometabolic disease because of uneven regional distribution of EAT around the heart, especially mostly located in the atrioventricular (AV) groove and interventricular (IV) groove [9-11]. Echocardiographic EAT measurement is a non-invasive and simple way to measure locationspecific EAT at the right ventricular free wall clinically [12-17]. Alternatively, CT (computed tomography) or MRI (magnetic resonance imaging) can also provide the simple but precise 2D measurement in the thickness of EAT in all cardiac segments $[11,18,19]$. Current evidence about the association between location-specific EAT thickness at the right ventricular free wall and coronary artery disease (CAD) is still controversial. Several studies using echocardiography have demonstrated a significant relationship between CAD and location-specific EAT thickness measured at right ventricular free wall $[13,14,16,17]$, while some studies using echocardiography or CT failed to observe a significant association $[11,12,19,20]$. Recent evidence has suggested that there is increasing attention on location-specific EAT thickness at the left AV groove as a potentially new biomarker associated with cardiometabolic risks by using 2D CT or MR measurement $[11,19,21,22]$. In this study, we conducted a meta-analysis to study the relationship between location-specific EAT thickness and obstructive $\mathrm{CAD}$, which may serve as a reliable predictor and improve CAD risk stratification in the future.

\section{Methods}

This meta-analysis was conducted according to the Meta-analysis Of Observational Studies in Epidemiology (MOOSE) statement [23].

\section{Search strategy}

We searched the Pubmed, Ovid Medline, Ovid Embase and Cochrane databases for relevant articles. Reviews were independently performed by two authors using the following search terms: "epicardial adipose tissue", "epicardial fat", "subepicardial adipose tissue", "subepicardial fat", "coronary artery disease [Mesh]", "atherosclerosis [Mesh]", and "cardiovascular disease [Mesh]", from the beginning of publication until January 2014. No language restrictions were applied. The pre-specified inclusion criteria were as follows: (a) observational studies to investigate the relationship between location-specific EAT thickness and CAD measured by echocardiography, CT or MRI-based quantitative measurements; (b) subjects with suspicion of CAD or at high risk of CAD clinically, and then subsequently divided into CAD and non-CAD groups assessed by coronary angiography, coronary CT angiography and coronary MR angiography. CAD group was defined as luminal stenosis $\geq 50 \%$ in one or more coronary arteries; and (c) for each study, the mean difference, standard deviation (SD) and sample size of subjects of $\mathrm{CAD}$ and non-CAD groups were reported in the literature. References within studies that met the inclusion criteria were reviewed for any possible missing relevant articles. Studies were excluded if any of the inclusion criteria were not met. All 10 published studies that met these inclusion criteria were considered eligible for further meta-analysis.

\section{Data extraction and quality assessment}

Data were abstracted and quality of studies was assessed independently by two reviewers (F.Z.W. and M.T.W.). Disagreement on specific studies between the two reviewers was resolved by consensus. Data were extracted from each study including the sample size and mean difference $\pm S D$ in location-specific EAT thickness in both $C A D$ and non-CAD groups (regrouping and calculating the mean difference and mixed SD in the study of Eroglu et al. [14]). Methodological study quality was assessed using the Strengthening of Reporting of Observational Studies in Epidemiology (STROBE) checklist of 22 items [24].

\section{Data analysis}

All statistical analyses were performed using the Comprehensive Meta-Analysis version 2 (Biostat, Englewood, New Jersey) and the Review Manager 5.0 software, available through the Cochrane Collaboration. Both fixed- and random-effects models were used for analysis of the standardized mean difference (SMD) in the CAD and nonCAD group. Heterogeneity was assessed and quantified using Cochran's Q statistic and the $\mathrm{I}^{2}$ statistic [25]. If $\mathrm{I}^{2}$ was below $30 \%$, fixed effects were chosen; if $\mathrm{I}^{2}$ was equal to or greater than $30 \%$, then random effects were applied [26]. Before the analysis, we formed a prior hypothesis that if heterogeneity existed in the studies, the source could be due to: (1) diagnostic tool for CAD (coronary angiography vs. coronary CT angiography); (2) ethnicity (Asian vs. nonAsian); (3) measurement tool of EAT (echocardiography vs. $\mathrm{CT}$ ); and (4) body mass index (BMI). We also performed subgroup and univariate meta-regression analyses to investigate potential sources of variability. Publication bias was assessed if available by using Egger's test to examine the likely presence of publication bias. 


\section{Results}

\section{Study identification and selection}

Overall, 312 articles were initially identified according to the broad criteria. After the initial screening of the title and abstract, 21 potentially relevant articles were retrieved for detailed review of their full text. Many studies that investigated the association between epicardial fat volume and $\mathrm{CAD}$ were excluded in this step.

In all these relevant studies, 11 studies were excluded after the detail review of their full text. Of these 11 studies, five studies were excluded because they did not report the detailed data for the meta-analysis [27-31]; two studies were excluded because of an investigation of the relationship between the EAT volume or area with CAD [32,33]; two studies were excluded because the study subjects were not well-defined or did not meet the criteria [15,34]; and the remaining two were letters and experimental studies $[5,35]$. The remaining 10 observational studies were eligible for the meta-analysis $[11-14,16,17,19-21,36]$. The flowchart of the search and selection of studies in this meta-analysis is illustrated in Figure 1. Overall, these studies included 1625 patients (924 subjects with CAD, and 701 subjects without CAD).

Table 1 summarize the characteristics of the nine observational studies investigating the association between location-specific EAT thickness at the right ventricular free wall and obstructive CAD. Table 2 summarizes the characteristics of the three observational studies investigating the association between location-specific EAT thickness at the left AV groove and obstructive CAD.

\section{Location-specific EAT thickness at the right ventricular free wall and obstructive CAD}

With regard to the association between the locationspecific EAT thickness at the right ventricular free wall and obstructive CAD, there was a significant difference in the SMD between CAD and no-CAD groups $(0.70 \mathrm{~mm}$, 95\% CI: 0.26-1.13, $\mathrm{p}=0.002$ ) in a random-effect pooled analysis of these studies (fixed-effect model in the Additional file 1: Figure S1). Statistically significant heterogeneity was observed in the study results $(\mathrm{p}<$ $\left.0.00001, \mathrm{I}^{2}=93 \%\right)$. There was no indication of publication bias with Egger's test $(\mathrm{p}=0.229$, funnel plot shown in Additional file 2: Figure S2). A sensitivity analysis, in which one study was removed at a time, was performed to evaluate the stability of the results. Results were similar in all sensitivity analyses.

Subgroup analyses were performed in an attempt to explore the possible causes of heterogeneity, according to ethnicity, diagnostic tools for $\mathrm{CAD}$, and measurement tool of EAT thickness. In subgroup analysis according to ethnicity shown in Table 3, the test for subgroup differences did not show a significant interaction. In contrast, the test for subgroup differences showed a significant interaction in the subgroup analysis according to diagnostic tools for CAD. In addition, the test for subgroup differences showed a significant interaction according to measurement tool of EAT thickness. In the subgroup of echocardiography-based studies, the random-effects model was used for the analysis, because the test for heterogeneity was statistically significant $\left(\mathrm{p}<0.00001 ; \mathrm{I}^{2}=94 \%\right)$. There was a significant difference in the SMD between CAD and no-CAD groups (0.98 mm, 95\% CI: 0.43-1.53, $\mathrm{p}=0.0005)$.

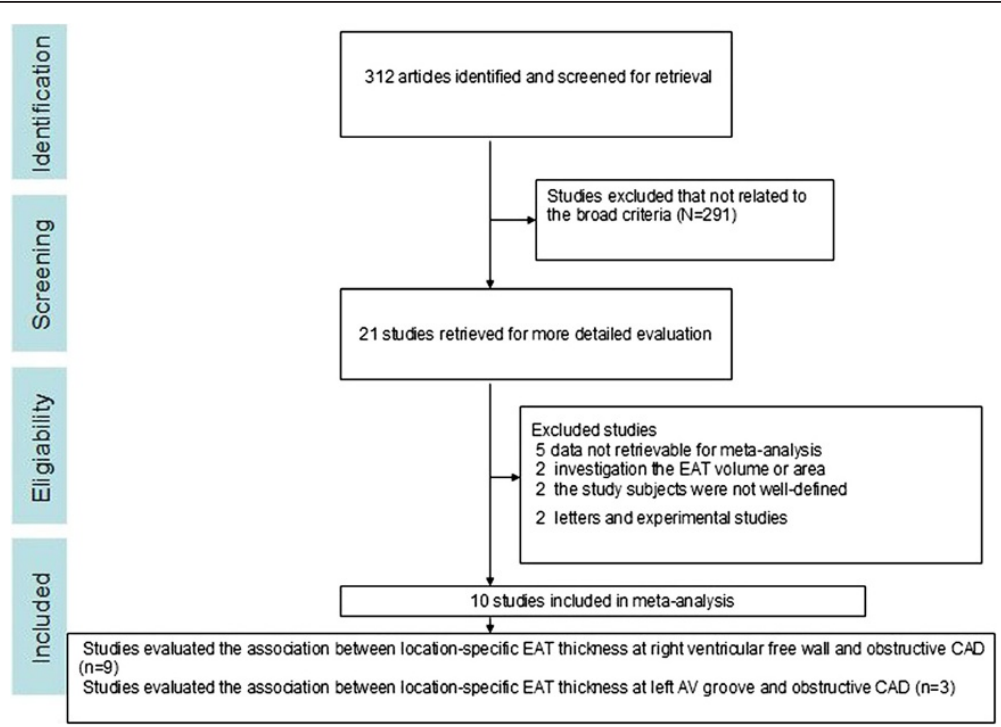

Figure 1 Flowchart of study selection process to determine the studies to be included in the meta-analysis. EAT, epicardial adipose tissue. 
Table 1 Demographics of included studies in the association between location-specific EAT thickness at the right ventricular free wall and obstructive CAD

\begin{tabular}{|c|c|c|c|c|c|c|c|c|c|c|c|c|c|}
\hline \multirow[b]{2}{*}{ References } & \multirow[b]{2}{*}{ Time } & \multirow[b]{2}{*}{$\begin{array}{c}\text { No. of } \\
\text { patients }\end{array}$} & \multicolumn{3}{|c|}{$\begin{array}{l}\text { CAD group } \\
\text { EAT thickness } \\
(\mathrm{mm})\end{array}$} & \multicolumn{3}{|c|}{$\begin{array}{l}\text { Non-CAD group } \\
\text { EAT thickness } \\
(\mathrm{mm})\end{array}$} & \multirow[b]{2}{*}{$\begin{array}{c}\text { BMI } \\
\left(\mathrm{kg} / \mathrm{m}^{2}\right)\end{array}$} & \multirow[b]{2}{*}{ Diagnostic tool } & \multirow[b]{2}{*}{$\begin{array}{l}\text { Measurement } \\
\text { tool }\end{array}$} & \multirow[b]{2}{*}{ Ethnicity } & \multirow[b]{2}{*}{$\begin{array}{l}\text { Study } \\
\text { quality }\end{array}$} \\
\hline & & & Mean & SD & Total & Mean & SD & Total & & & & & \\
\hline Chaowalit et al. [12] & 2006 & 139 & 2.22 & 1.86 & 85 & 2.16 & 1.77 & 54 & $28.7 \pm 5.5$ & Coronary angiography & Echocardiography & Non-Asian & 20 \\
\hline Yun et al. [13] & 2009 & 153 & 3.8 & 1.9 & 85 & 1.8 & 1.4 & 68 & $25.2 \pm 3.1$ & Coronary angiography & Echocardiography & Asian & 21 \\
\hline Eroglu et al. [14] & 2009 & 150 & 7.3 & 1.2 & 80 & 4.68 & 1.13 & 70 & $28.9 \pm 4.5$ & Coronary angiography & Echocardiography & Non-Asian & 21 \\
\hline Wang et al. [11] & 2010 & 224 & 4.3 & 1.8 & 140 & 4.1 & 2.0 & 84 & $26.1 \pm 3.3$ & Coronary angiography & CT & Asian & 21 \\
\hline Bastarrika et al. [20] & 2010 & 45 & 8.57 & 2.08 & 23 & 7.69 & 2.68 & 22 & $29.1 \pm 5.7$ & Coronary angiography & CT & Non-Asian & 20 \\
\hline Mustelier et al. [16] & 2011 & 250 & 6.6 & 2.8 & 185 & 4.7 & 2.3 & 65 & $27.4 \pm 5.3$ & Coronary angiography & Echocardiography & Non-Asian & 19 \\
\hline Shemirani et al. [17] & 2012 & 292 & 5.4 & 1.9 & 171 & 4.4 & 1.8 & 121 & NR & Coronary angiography & Echocardiography & Non-Asian & 19 \\
\hline Wu et al. [19] & 2013 & 208 & 5.8 & 2.3 & 97 & 5.9 & 2.3 & 111 & $24.8 \pm 3.3$ & Coronary $\mathrm{CT}$ angiography & CT & Asian & 21 \\
\hline Kaya et al. [36] & 2013 & 64 & 6.43 & 0.9 & 34 & 5.35 & 0.75 & 30 & $26.0 \pm 3.0$ & Coronary angiography & Echocardiography & Non-Asian & 19 \\
\hline
\end{tabular}


Table 2 Demographics of included studies in the association between location-specific EAT thickness at left AV groove and obstructive CAD

CAD group Non-CAD group

EAT thickness $\quad$ EAT thickness

$(\mathrm{mm}) \quad(\mathrm{mm})$

\begin{tabular}{|c|c|c|c|c|c|c|c|c|c|c|c|c|c|}
\hline References & Time & $\begin{array}{c}\text { No. of } \\
\text { patients }\end{array}$ & Mean & SD & Total & Mean & SD & Total & $\begin{array}{c}\mathrm{BMI} \\
\left(\mathrm{kg} / \mathrm{m}^{2}\right)\end{array}$ & Diagnostic tool & $\begin{array}{c}\text { Measurement } \\
\text { tool }\end{array}$ & Ethnicity & $\begin{array}{c}\text { Study } \\
\text { quality }\end{array}$ \\
\hline Wang et al. [11] & 2010 & 224 & 13.2 & 3.1 & 140 & 11.3 & 2.5 & 84 & $26.1 \pm 3.3$ & Coronary angiography & CT & Asian & 21 \\
\hline Kim et al. [21] & 2012 & 100 & 13 & 2.6 & 24 & 11.5 & 2.1 & 76 & $25.3 \pm 3.2$ & Coronary MR angiography & MRI & Asian & 21 \\
\hline Wu et al. [19] & 2013 & 208 & 17.8 & 3.9 & 97 & 14.3 & 4.3 & 111 & $24.8 \pm 3.3$ & Coronary $C T$ angiography & $\mathrm{CT}$ & Asian & 21 \\
\hline
\end{tabular}

$\mathrm{BMI}$, body mass index; EAT, epicardial adipose tissue; $\mathrm{CAD}$, coronary artery disease; $\mathrm{CT}$, computed tomography; $\mathrm{AV}$, atrioventricular. 
Table 3 Subgroups analyses according to the ethnicity, diagnostic tool, and measurement tool comparing location-specific EAT thickness at the right ventricular free wall in subjects of CAD and non-CAD groups

\begin{tabular}{lcccc}
\hline Subgroups & Studies & Subjects & SMD $(\mathbf{9 5 \%} \mathrm{Cl})$ & $\mathbf{p}$ Value \\
\hline Ethnicity & 3 & 585 & $0.4(-0.28$ to 1.09$)$ & 0.36 \\
$\quad$ Asian & 6 & 940 & $0.80(0.30$ to 1.29$)$ & \\
$\quad \begin{array}{l}\text { Non-Asian } \\
\text { Diagnostic tool }\end{array}$ & & & & \\
$\quad \begin{array}{l}\text { Coronary } \\
\text { angiography }\end{array}$ & 8 & 1317 & $0.75(0.34$ to 1.16$)$ & 0.002 \\
$\begin{array}{l}\text { Coronary CT } \\
\text { angiography }\end{array}$ & 1 & 208 & $-0.04(-0.23$ to 0.32$)$ & \\
$\begin{array}{l}\text { Measurement tool } \\
\quad \text { Echocardiography }\end{array}$ & 6 & 1048 & $0.98(0.43$ to 1.53$)$ & 0.002 \\
$\quad$ CT & 3 & 477 & $0.06(0.17$ to 1.09$)$ & \\
\hline
\end{tabular}

$\mathrm{p}$ Value: test of interaction between subgroups. CAD, coronary artery disease; $S M D$, standardized mean difference; $C T$, computed tomography.

By contrast, there was no significant difference in the SMD between CAD and no-CAD groups $(0.06 \mathrm{~mm}$, 95\% CI: $-0.12-0.25, \mathrm{p}=0.50$ ) in the subgroup of CTbased studies, and greater homogeneity was also observed within this subgroup shown in Figure $2(\mathrm{p}=$ $0.43 ; \mathrm{I}^{2}=0$ ). Therefore, diagnostic tools for CAD and measurement tool of EAT thickness were the potential sources of heterogeneity between studies. In univariate random effects meta-regression analysis, BMI was not significantly associated with effect size shown in Figure 3 (95\% CI: $-0.24-0.17, \mathrm{p}=0.59$ ).
Location-specific EAT thickness at the left AV groove and obstructive CAD

Figure 4 shows the forest plot of the pooled results of the SMD of the three studies in order to investigation the association between obstructive CAD and EAT thickness at the left $\mathrm{AV}$ groove. In a fixed-effect pooled analysis, there was a significant difference in the SMD between CAD and noCAD groups $(0.74 \mathrm{~mm}, 95 \% \mathrm{CI}: 0.55-0.92, \mathrm{p}<0.00001)$, and low heterogeneity among the three studies shown in Figure $4\left(\mathrm{p}=0.61, \mathrm{I}^{2}=0 \%\right)$. Overall, location-specific EAT thickness at the left AV groove was significantly thicker in the CAD group than the no-CAD group. Publication bias was not assessed because of limited studies.

\section{Discussion}

The role of location-specific EAT thickness at the right ventricular free wall in obstructive CAD

With regard to the association between the locationspecific EAT thickness at the right ventricular free wall and obstructive CAD, the overall results of the metaanalysis in nine studies show a statistically significantly increase in EAT thickness at the right ventricular free wall in the CAD group than in the no-CAD group.

It should be clear that only the result of echocardiographybased studies (six studies) showed a significant association between CAD and the EAT thickness at right ventricular free wall, and the result of all included CT-based studies (three studies) showed a non-significant association. And low between-study heterogeneity was also observed in the CT-based studies (three studies) assessed at the right ventricular free wall. However, extreme between-study heterogeneity was also observed in the overall meta-analysis

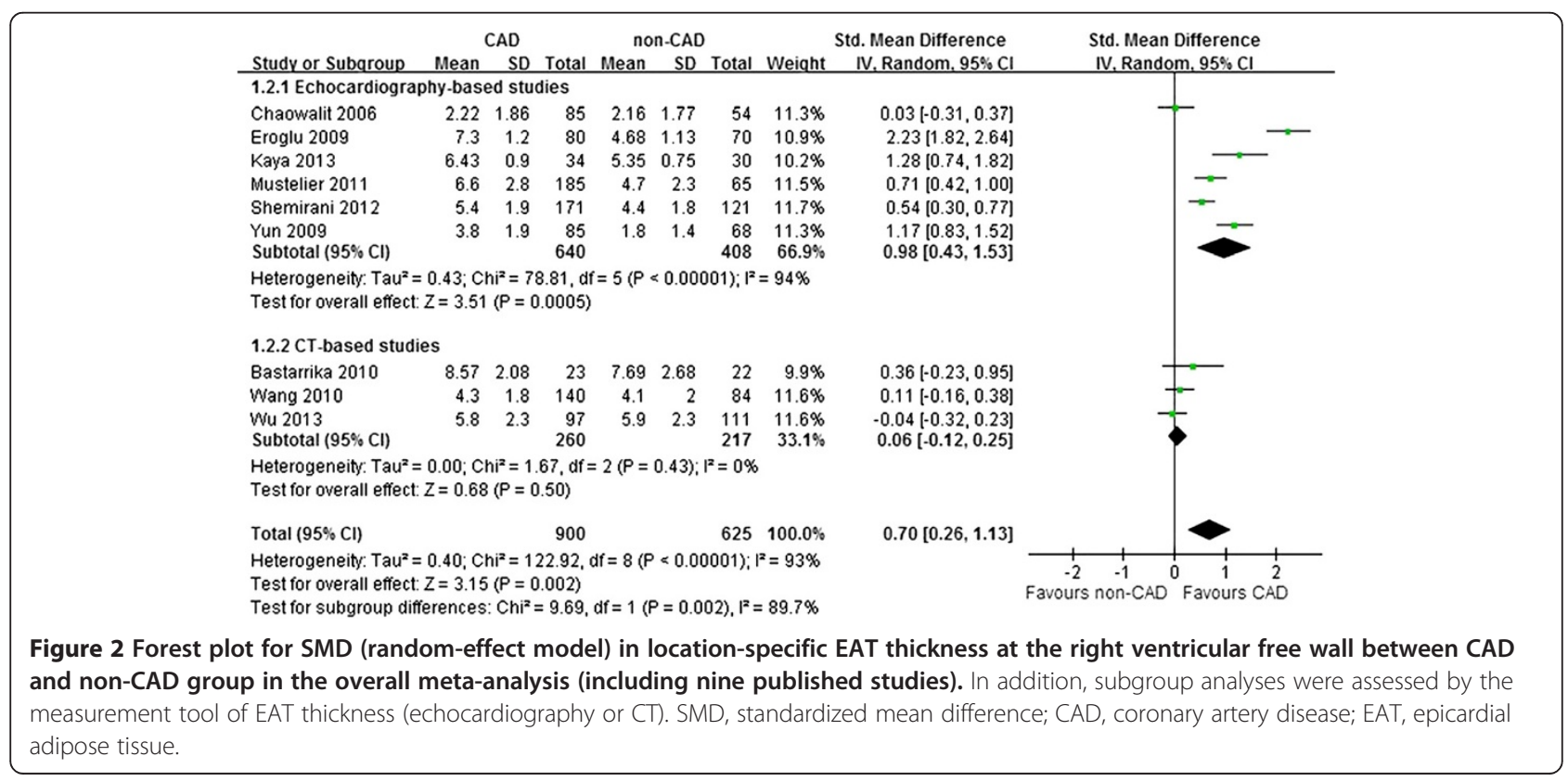




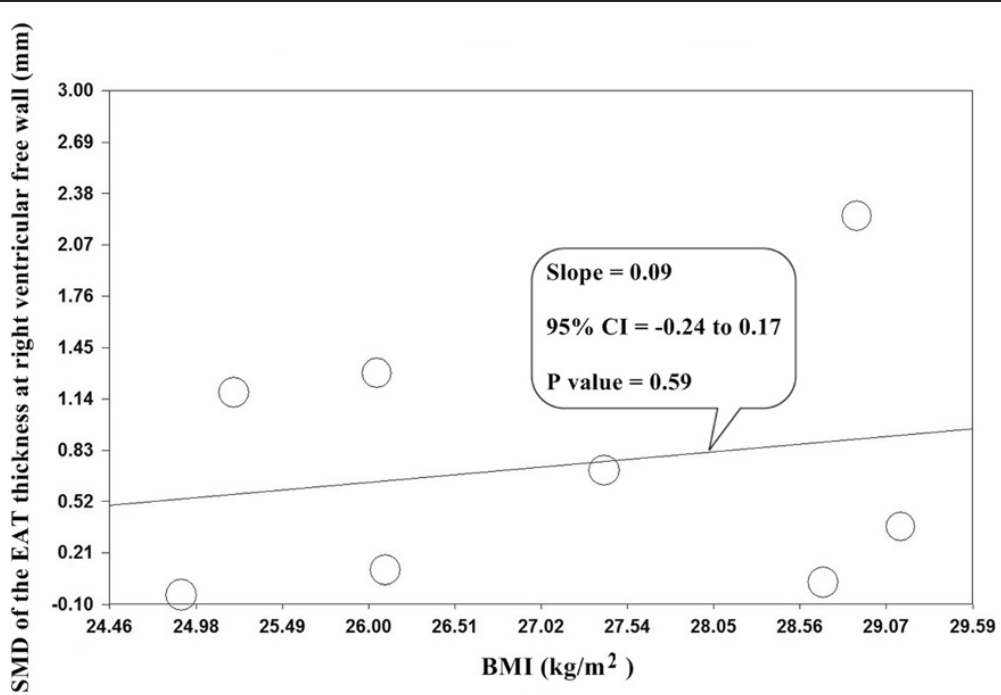

Figure 3 Meta-regression analysis between BMI and SMD of location-specific EAT thickness at right ventricular free wall. BMI, body mass index; SMD, standardized mean difference; EAT, epicardial adipose tissue.

(nine studies) and echocardiography-based studies (six studies). Therefore, all this evidence suggested that CTbased measurement may potentially be a more reliable tool than echocardiography-based measurement.

Regarding the association between location-specific EAT thickness at the right ventricular free wall and obstructive $C A D$, subgroup and meta-regression analyses for all covariates have been used to address the issues of heterogeneity between studies. A recent meta-analysis of worldwide study demonstrates a significant correlation between EAT and BMI, but shows a relationship between EAT and metabolic syndrome independent of BMI [37]. These findings support the meta-regression analysis in our study that revealed BMI was not considered a potential source of heterogeneity between eight studies.

We think a possible explanation for the high heterogeneity between studies was that the difference in reliability and reproducibility between the two tools (echocardiography vs. CT) should be seriously concerned. In comparison with CT-based measurement, echocardiography is a non-invasive imaging modality in EAT measurement that requires less cost and is less time-consuming. However, a recent study has shown the poor reproducibility of echocardiographic EAT measurements assessed by intraclass correlation coefficient, and low concordance observed between $\mathrm{CT}$ and echocardiographic measurement [38]. One the contrary, several studies have demonstrated high interobserver reliability and intraobserver reproducibility of EAT thickness measured by CT $[11,39,40]$. Potential measurement bias in the EAT measurement by echocardiography may contribute to the disparate results between echocardiography-based and CT-based studies. And recent longitudinal studies have also demonstrated nonassociation between EAT thickness assessed by echocardiography and cardiac events or major adverse cardiac events (MACE) [29,31], which also supports the negative result by CT-based studies in the subgroup analysis. Therefore, we suggest that the effect of location-specific EAT at the right ventricular free wall on $C A D$ is still uncertain. However, future well-designed studies are warranted because of limited CT-based studies measuring locationspecific EAT thickness at the right ventricular free wall.

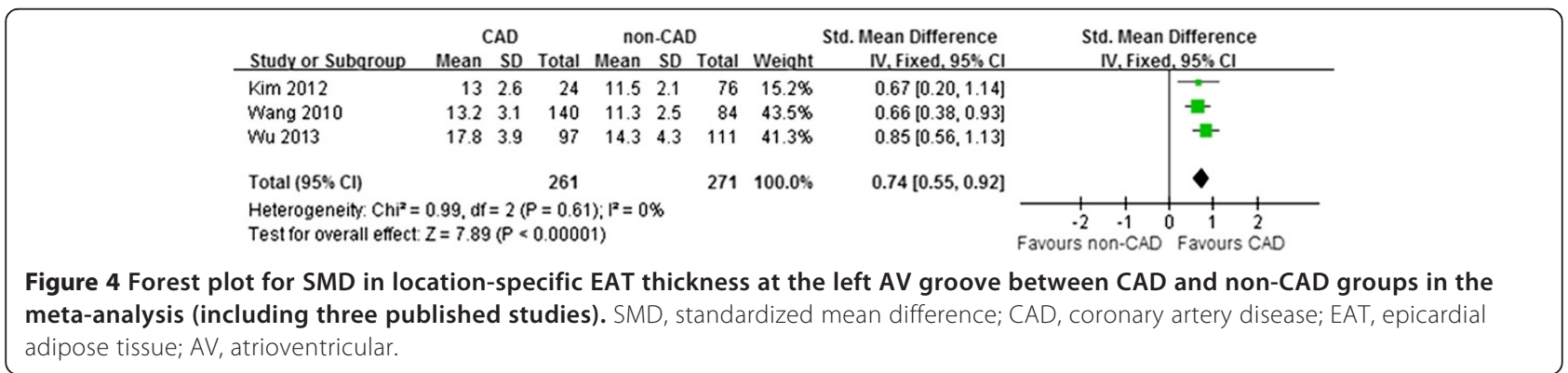




\section{The role of location-specific EAT thickness at the left AV groove in obstructive CAD}

With regard to the association between the locationspecific EAT thickness at the left AV groove and obstructive $\mathrm{CAD}$, the results from the current meta-analysis indicate increased location-specific EAT thickness at the left AV groove was associated with obstructive CAD assessed by CT or MRI.

And high homogeneity between studies was observed, despite diagnosis of CAD in different imaging modalities, including coronary angiography, coronary CT angiography and MR coronary angiography. Substantial evidence has also supported the diagnostic accuracy of coronary CT angiography and MR coronary angiography in the evaluation of coronary arteries stenosis [41-43].

While there is no obvious explanation for this observation, uneven regional distribution of EAT around the heart may provide clues. Recent studies also suggest that location-specific EAT thickness at the left AV groove may play a important causal role in cardiometabolic disease through a possible mechanism described by Wang et al. [11] whereby diffusion of EAT paracrine metabolites through thin-walled coronary venous networks into the coronary sinus is due to abundant coronary venous sinus drainage networks in the left AV groove. In addition, location-specific EAT thickness at the left AV groove can be easily and reliably assessed in 2D-based CT or MRI images available in routine clinical practice for cardiovascular risk assessment $[11,19,21]$. Taken together, these findings may indicate that combined measurement of EAT thickness in the left AV groove and coronary calcium score provides more in-depth information than conventional risk factor assessment in CAD prediction [44]. Because of the limited number of studies almost exclusively in Asian populations, future welldesigned cohort studies are warranted to investigate the cause-effect relationship by CT or MRI.

\section{Study strengths and limitations}

It is our belief that the present study has demonstrated certain advantages over the previous meta-analysis [45]. First, in contrast to previous meta-analysis by $\mathrm{Xu}$ et al. [45] on this topic, we used explicit criteria to define inclusion criteria. To investigate the association between regional EAT thickness and CAD, we select the locationspecific EAT thickness at the right ventricular free wall or left AV groove by echocardiography, CT or MRI rigorously. However, the previous meta-analysis has used these data of the "average" EAT thickness extracted from the study by Wang et al. [11]. Second, the aims of the previous metaanalysis and our study were both to investigate the relationship between EAT thickness and CAD. We found one included study in the previous meta-analysis that investigated the relationship between regional EAT thickness and descending thoracic aorta atherosclerosis [46], instead of all included nine studies rigorously assessing obstructive CAD in our study. Third, study quality was assessed using the STROBE statement to ensure that all studies reach a level of quality in this meta-analyses.

The current study had several potential limitations. First, all ten included studies in the present metaanalysis were case-control or cross-sectional studies despite assessing study quality using the STROBE statement, which has limitations in providing definite information about the cause-and-effect relationship. In addition, the best evidence comes primarily from meta-analyses of randomized controlled trials. Second, there are many confounding factors associated with $\mathrm{CAD}$, such as the Framingham risk score and CAC score were not considered in this meta-analyses. However, we have investigated a number of factors to explore between-study heterogeneity. The included studies were different in diagnostic tools for CAD and measurement tools of EAT, which may contribute to the heterogeneity among the studies. Third, there are limited studies in assessing the association between left AVG EAT thickness and obstructive CAD despite recognition that homogeneity exists between studies, which may lead to insufficient evidence to support the result.

\section{Conclusion}

In summary, our meta-analysis suggests that significantly elevated location-specific EAT thickness at the left AV groove is associated with obstructive CAD, and homogeneity influenced agreement between studies. Based on the current evidence, the location-specific EAT thickness at the left AV groove appears to play an influential role in the prediction of obstructive CAD, especially in Asian populations. In addition, adding EAT thickness at the left AV groove on top of clinical CAD risk factors plus Agatston score may provide further evidence in predicting CAD in the population with suspicion of CAD $[19,44]$. Subsequent, large, more definitive studies are needed to confirm these findings and to establish if location-specific EAT thickness at the left AV groove be used in clinical context.

\section{Additional files}

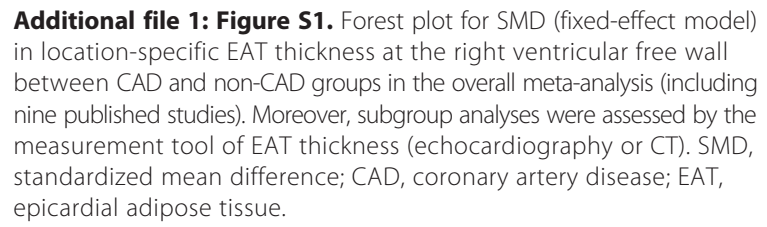

Additional file 1: Figure S1. Forest plot for SMD (fixed-effect model) in location-specific EAT thickness at the right ventricular free wall between CAD and non-CAD groups in the overall meta-analysis (including nine published studies). Moreover, subgroup analyses were assessed by the measurement tool of EAT thickness (echocardiography or CT). SMD, standardized mean difference; CAD, coronary artery disease; EAT, epicardial adipose tissue.

Additional file 2: Figure S2. Funnel plot for potential publication bias in the overall meta-analysis of the association between location-specific EAT at the right ventricular free wall and obstructive CAD, including nine studies. EAT, epicardial adipose tissue; CAD, coronary artery disease. 


\section{Abbreviations}

AV: Atrioventricular; BMl: Body mass index; CAC: Coronary arterial calcification; CAD: Coronary artery disease; CT: Computed tomography; EAT: Epicardial adipose tissue; MRI: Magnetic resonance imaging; MOOSE statement: Meta-analysis Of Observational Studies in Epidemiology statement; SD: Standard deviation; SMD: Standardized mean difference; STROBE checklist: Strengthening of Reporting of Observational Studies in Epidemiology checklist; MACE: Major adverse cardiac events.

\section{Competing interests}

The authors declare that they have no competing interests.

\section{Authors' contributions}

FZW and MTW participated in the conception, design of the study, collected the data, performed statistical analyses, and drafted the manuscript. YLH and KJC helped to collect data and draft the manuscript. All authors read and approved the final manuscript.

\section{Acknowledgements}

We are grateful to Dr. Carol C. Wu for reviewing the manuscript. This study was supported by Grants from National Science Council NSC97-2314-B-010045-MY3 and Kaohsiung Veterans General Hospital, VGHKS101-020, VGHKS100-074, Taiwan, R.O.C.

\section{Author details}

'Department of Radiology, Section of Thoracic and Circulation Imaging, Kaohsiung Veterans General Hospital, Kaohsiung, Taiwan. ${ }^{2}$ Centre for Evidence-Based Medicine, Kaohsiung Veterans General Hospital, Kaohsiung, Taiwan. ${ }^{3}$ Faculty of Medicine, School of Medicine, National Yang Ming University, Taipei, Taiwan. ${ }^{4}$ Department of Internal Medicine, Kaohsiung Veterans General Hospital, Kaohsiung, Taiwan.

Received: 7 March 2014 Accepted: 28 April 2014

Published: 4 May 2014

\section{References}

1. Mazurek T, Zhang L, Zalewski A, Mannion JD, Diehl JT, Arafat H, Sarov-Blat L, O'Brien S, Keiper EA, Johnson AG, Martin J, Goldstein BJ, Shi Y: Human epicardial adipose tissue is a source of inflammatory mediators. Circulation 2003, 108(20):2460-2466

2. Baker A, da Silva N, Quinn D, Harte A, Pagano D, Bonser R, Kumar S, McTernan P: Human epicardial adipose tissue expresses a pathogenic profile of adipocytokines in patients with cardiovascular disease. Cardiovasc Diabetol 2006, 5(1):1-7.

3. Sacks HS, Fain JN: Human epicardial adipose tissue: a review. Am Heart $J$ 2007, 153(6):907-917.

4. lacobellis G, Corradi D, Sharma AM: Epicardial adipose tissue: anatomic, biomolecular and clinical relationships with the heart. Nat Clin Pract Cardiovasc Med 2005, 2(10):536-543.

5. lacobellis G, Pistilli D, Gucciardo M, Leonetti F, Miraldi F, Brancaccio G, Gallo $P$, di Gioia CR: Adiponectin expression in human epicardial adipose tissue in vivo is lower in patients with coronary artery disease. Cytokine 2005, 29(6):251-255

6. Iwasaki K, Matsumoto T, Aono H, Furukawa H, Samukawa M: Relationship between epicardial fat measured by 64-multidetector computed tomography and coronary artery disease. Clin Cardiol 2011, 34(3):166-171.

7. Rosito GA, Massaro JM, Hoffmann U, Ruberg FL, Mahabadi AA, Vasan RS, O'Donnell CJ, Fox CS: Pericardial fat, visceral abdominal fat, cardiovascular disease risk factors, and vascular calcification in a community-based sample: the Framingham Heart Study. Circulation 2008, 117(5):605-613.

8. Ahmadi N, Nabavi V, Yang E, Hajsadeghi F, Lakis M, Flores F, Zeb I, Bevinal M, Ebrahimi R, Budoff M: Increased epicardial, pericardial, and subcutaneous adipose tissue is associated with the presence and severity of coronary artery calcium. Acad Radiol 2010, 17(12):1518-1524.

9. Gorter PM, de Vos AM, van der Graaf Y, Stella PR, Doevendans PA, Meijs MF, Prokop M, Visseren FL: Relation of epicardial and pericoronary fat to coronary atherosclerosis and coronary artery calcium in patients undergoing coronary angiography. Am J Cardiol 2008, 102(4):380-385.

10. de Vos AM, Prokop M, Roos CJ, Meijs MF, van der Schouw YT, Rutten A, Gorter PM, Cramer MJ, Doevendans PA, Rensing BJ, Bartelink ML, Velthuis BK, Mosterd A, Bots ML: Peri-coronary epicardial adipose tissue is related to cardiovascular risk factors and coronary artery calcification in postmenopausal women. Eur Heart J 2008, 29(6):777-783.

11. Wang TD, Lee WJ, Shih FY, Huang CH, Chen WJ, Lee YT, Shih TT, Chen MF: Association of epicardial adipose tissue with coronary atherosclerosis is region-specific and independent of conventional risk factors and intra-abdominal adiposity. Atherosclerosis 2010, 213(1):279-287.

12. Chaowalit N, Somers VK, Pellikka PA, Rihal CS, Lopez-Jimenez F: Subepicardial adipose tissue and the presence and severity of coronary artery disease. Atherosclerosis 2006, 186(2):354-359.

13. Yun KH, Rhee SJ, Yoo NJ, Oh SK, Kim NH, Jeong JW, Park DS, Park HY. Relationship between the Echocardiographic Epicardial Adipose Tissue Thickness and Serum Adiponectin in Patients with Angina. J Cardiovasc Ultrasound 2009, 17(4):121-126.

14. Eroglu S, Sade LE, Yildirir A, Bal U, Ozbicer S, Ozgul AS, Bozbas H, Aydinalp A, Muderrisoglu $\mathrm{H}$ : Epicardial adipose tissue thickness by echocardiography is a marker for the presence and severity of coronary artery disease. Nutr Metab Cardiovasc Dis 2009, 19(3):211-217.

15. lacobellis G, Lonn E, Lamy A, Singh N, Sharma AM: Epicardial fat thickness and coronary artery disease correlate independently of obesity. Int J Cardiol 2011, 146(3):452-454.

16. Mustelier JV, Rego JOC, González AG, Sarmiento JCG, Riverón BV: Parâmetros ecocardiográficos de deposição de gordura epicárdica e sua relação com doença arterial coronariana. Ara Bras Cardiol 2011, 97:122-129.

17. Shemirani $\mathrm{H}$, Khoshavi M: Correlation of echocardiographic epicardial fat thickness with severity of coronary artery disease-an observational study. Anadolu Kardiyol Derg 2012, 12(3):200-205.

18. Liang KW, Tsai IC, Lee WJ, Lee IT, Lee WL, Lin SY, Wan CJ, Fu CP, Ting CT, Sheu WH: MRI measured epicardial adipose tissue thickness at the right AV groove differentiates inflammatory status in obese men with metabolic syndrome. Obesity (Silver Spring) 2012, 20(3):525-532.

19. Wu FZ, Huang YL, Wang YC, Lin HS, Chen CS, Ju YJ, Chiou KR, Cheng CC, WU MT: Impact of location of epicardial adipose tissue, measured by coronary artery calcium-scoring computed tomography on obstructive coronary artery disease. Am J Cardio/ 2013, 112(7):943-949.

20. Bastarrika G, Broncano J, Schoepf UJ, Schwarz F, Lee YS, Abro JA, Costello P, Zwerner PL: Relationship between coronary artery disease and epicardial adipose tissue quantification at cardiac CT: comparison between automatic volumetric measurement and manual bidimensional estimation. Acad Radiol 2010, 17(6):727-734.

21. Kim HM, Kim KJ, Lee HJ, Yu HT, Moon JH, Kang ES, Cha BS, Lee HC, Lee BW, Kim YJ: Epicardial adipose tissue thickness is an indicator for coronary artery stenosis in asymptomatic type 2 diabetic patients: its assessment by cardiac magnetic resonance. Cardiovasc Diabetol 2012, 11:83.

22. Wang TD, Lee WJ, Shih FY, Huang CH, Chang YC, Chen WJ, Lee YT, Chen MF: Relations of epicardial adipose tissue measured by multidetector computed tomography to components of the metabolic syndrome are region-specific and independent of anthropometric indexes and intraabdominal visceral fat. J Clin Endocrinol Metab 2009, 94(2):662-669.

23. Stroup DF, Berlin JA, Morton SC, Olkin I, Williamson GD, Rennie D, Moher D, Becker BJ, Sipe TA, Thacker SB: Meta-analysis of observational studies in epidemiology: a proposal for reporting. Meta-analysis Of Observational Studies in Epidemiology (MOOSE) group. JAMA 2000, 283(15):2008-2012.

24. von Elm E, Altman DG, Egger M, Pocock SJ, Gotzsche PC, Vandenbroucke JP The Strengthening the Reporting of Observational Studies in Epidemiology (STROBE) statement: guidelines for reporting observational studies. PLoS Med 2007, 4(10):e296.

25. Higgins JP, Thompson SG, Deeks JJ, Altman DG: Measuring inconsistency in meta-analyses. BMJ 2003, 327(7414):557-560

26. DerSimonian R, Kacker R: Random-effects model for meta-analysis of clinical trials: an update. Contemp Clin Trials 2007, 28(2):105-114.

27. Ahn SG, Lim HS, Joe DY, Kang SJ, Choi BJ, Choi SY, Yoon MH, Hwang GS, Tahk SJ, Shin JH: Relationship of epicardial adipose tissue by echocardiography to coronary artery disease. Heart 2008, 94(3):e7.

28. Jeong JW, Jeong MH, Yun KH, Oh SK, Park EM, Kim YK, Rhee SJ, Lee EM, Lee J, Yoo NJ, Kim NH, Park JC: Echocardiographic epicardial fat thickness and coronary artery disease. Circ J 2007, 71(4):536-539.

29. Kaushik M, Saurav A, Smer A, Alla VM, Khan S, Madan R, Holmberg MJ, Mohiuddin S: Epicardial adipose tissue as assessed by echocardiography and incident cardiac disease. J Am Coll Cardiol 2012, 59(13s1):E1159.

30. Nelson MR, Mookadam F, Thota V, Emani U, Al Harthi M, Lester SJ, Cha S, Stepanek J, Hurst RT: Epicardial fat: an additional measurement for 
subclinical atherosclerosis and cardiovascular risk stratification? J Am Soc Echocardiogr 2011, 24(3):339-345.

31. Albuquerque FN, Somers VK, Blume G, Miranda W, Korenfeld Y, Calvin AD, Qin R, Lopez-Jimenez F: Usefulness of epicardial adipose tissue as predictor of cardiovascular events in patients with coronary artery disease. Am J Cardiol 2012, 110(8):1100-1105.

32. Bettencourt N, Toschke AM, Leite D, Rocha J, Carvalho M, Sampaio F, Xara S, Leite-Moreira A, Nagel E, Gama V: Epicardial adipose tissue is an independent predictor of coronary atherosclerotic burden. Int J Cardiol 2012, 158(1):26-32.

33. Sironi AM, Petz R, De Marchi D, Buzzigoli E, Ciociaro D, Positano V, Lombardi M, Ferrannini E, Gastaldelli A: Impact of increased visceral and cardiac fat on cardiometabolic risk and disease. Diabet Med 2012, 29(5):622-627.

34. Bachar GN, Dicker D, Kornowski R, Atar E: Epicardial adipose tissue as a predictor of coronary artery disease in asymptomatic subjects. Am J Cardiol 2012, 110(4):534-538.

35. Cabrera-Rego JO: Echocardiographic measurement of epicardial fat thickness: in search for a consensus/Correlation of echocardiographic epicardial fat thickness with severity of coronary artery disease-an observational study. Anadolu Kardiyol Derg 2012, 12(5):448-449. author reply 449 .

36. Kaya H, Ertas F, Oylumlu M, Bilik MZ, Yildiz A, Yuksel M, Polat $N$, Acet $H$, Isik F, Ulgen MS: Relation of epicardial fat thickness and brachial flow-mediated vasodilation with coronary artery disease. J Cardiol 2013, 62(6):343-347.

37. Rabkin SW: The relationship between epicardial fat and indices of obesity and the metabolic syndrome: a systematic review and meta-analysis. Metab Syndr Relat Disord 2014, 12(1):31-42.

38. Saura D, Oliva MJ, Rodriguez D, Pascual-Figal DA, Hurtado JA, Pinar E, de la Morena G, Valdes M: Reproducibility of echocardiographic measurements of epicardial fat thickness. Int J Cardiol 2010 141(3):311-313.

39. Abbara S, Desai JC, Cury RC, Butler J, Nieman K, Reddy V: Mapping epicardial fat with multi-detector computed tomography to facilitate percutaneous transepicardial arrhythmia ablation. Eur J Radiol 2006, 57(3):417-422

40. Gorter PM, van Lindert AS, de Vos AM, Meijs MF, van der Graaf $Y$, Doevendans PA, Prokop M, Visseren FL: Quantification of epicardial and peri-coronary fat using cardiac computed tomography; reproducibility and relation with obesity and metabolic syndrome in patients suspected of coronary artery disease. Atherosclerosis 2008, 197(2):896-903

41. Yonezawa M, Nagata M, Kitagawa K, Kato S, Yoon Y, Nakajima H, Nakamori S, Sakuma H, Hatakenaka M, Honda H: Quantitative analysis of 1.5-T whole-heart coronary MR angiograms obtained with 32-channel cardiac coils: a comparison with conventional quantitative coronary angiography. Radiology 2014, 271(2):356-364.

42. Meijboom WB, Meijs MF, Schuijf JD, Cramer MJ, Mollet NR, van Mieghem CA, Nieman K, van Werkhoven JM, Pundziute G, Weustink AC, de Vos AM, Pugliese F, Rensing B, Jukema JW, Bax JJ, Prokop M, Doevendans PA, Hunink MG, Krestin GP, de Feyter PJ: Diagnostic accuracy of 64-slice computed tomography coronary angiography: a prospective, multicenter, multivendor study. J Am Coll Cardiol 2008, 52(25):2135-2144.

43. Budoff MJ, Dowe D, Jollis JG, Gitter M, Sutherland J, Halamert E, Scherer M, Bellinger R, Martin A, Benton R, Delago A, Min JK: Diagnostic performance of 64-multidetector row coronary computed tomographic angiography for evaluation of coronary artery stenosis in individuals without known coronary artery disease: results from the prospective multicenter ACCURACY (Assessment by Coronary Computed Tomographic Angiography of Individuals Undergoing Invasive Coronary Angiography) trial. J Am Coll Cardiol 2008, 52(21):1724-1732.

44. Canpolat U, Ozcan F, Ozeke O, Turak O, Aydogdu S: Usefulness of screening left atrioventricular groove epicardial adipose tissue thickness. Am J Cardiol 2013, 112(7):1054-1055.
45. Xu Y, Cheng X, Hong K, Huang C, Wan L: How to interpret epicardial adipose tissue as a cause of coronary artery disease: a meta-analysis. Coron Artery Dis 2012, 23(4):227-233.

46. Yorgun $\mathrm{H}$, Canpolat U, Hazirolan T, Sunman H, Ates AH, Gurses KM, Ertugrul O, Kaya EB, Aytemir K, Tokgozoglu L, Kabakci G, Oto A: Epicardial adipose tissue thickness predicts descending thoracic aorta atherosclerosis shown by multidetector computed tomography. Int J Cardiovasc Imaging 2012, 28(4):911-919.

doi:10.1186/1471-2261-14-62

Cite this article as: Wu et al:: The relation of location-specific epicardial adipose tissue thickness and obstructive coronary artery disease: systemic review and meta-analysis of observational studies. BMC Cardiovascular Disorders 2014 14:62.

\section{Submit your next manuscript to BioMed Central and take full advantage of:}

- Convenient online submission

- Thorough peer review

- No space constraints or color figure charges

- Immediate publication on acceptance

- Inclusion in PubMed, CAS, Scopus and Google Scholar

- Research which is freely available for redistribution

Submit your manuscript at www.biomedcentral.com/submit
() Biomed Central 